Meta

Journal des traducteurs

Translators' Journal

\title{
SI: A Note on Error Typologies and the Possibility of Gaining insight in Mental Processes
}

\section{P. A. Jensen}

Volume 30, numéro 1, mars 1985

Interprétation de conférence

URI : https://id.erudit.org/iderudit/003262ar

DOI : https://doi.org/10.7202/003262ar

Aller au sommaire du numéro

Éditeur(s)

Les Presses de l'Université de Montréal

ISSN

0026-0452 (imprimé)

1492-1421 (numérique)

Découvrir la revue

Citer cet article

Jensen, P. A. (1985). SI: A Note on Error Typologies and the Possibility of Gaining insight in Mental Processes. Meta, 30(1), 106-113.

https://doi.org/10.7202/003262ar d'utilisation que vous pouvez consulter en ligne. 


\title{
SI : A NOTE ON ERROR TYPOLOGIES AND THE POSSIBILITY OF GAINING INSIGHT IN MENTAL PROCESSES ${ }^{*}$
}

P.A. JENSEN

\author{
IMPLICATIONS OF FORMAL SYNTACTIC THEORY FOR SI RESEARCH
}

\section{INTRODUCTORY REMARKS}

Forming the theory of SI would probably be one of the most difficult and daring projects in the history of the human sciences. The SI process is so versatile that the number of variables involved is presumably infinite and, what is worse, some variable types may belong to incompatible logical classes, e.g. 'encyclopedic knowledge' does not belong to the same logical category as 'linguistic knowledge', but no one would deny that both are crucially involved in SI. Hence, a unified theory of SI is not likely to be viable and a "modular approach" to the field seems to be advisable. By "modular approach" I mean the methodological necessity of splitting up an area into smaller units which can be studied in relative isolation from other areas of the same field, even though from a superficial point of view the modules may seem to form an inextricable whole. Thus, "module" is not an explicated term as yet, and the question "What modules are involved in SI ?" is only answerable in terms of a theory which covers as much of the SI process as is possible at any given time.

What I would like to suggest, however, is that formal aspects of language, syntax in particular, may play a more important role in SI than is commonly assumed, i.e. I would like to propose that any adequate theory of SI must include a "formal module". The general view seems to be that formal aspects of language can safely be either neglected in SI research or, at best, given relatively minor attention due to certain outdated ideas about language relationships. An example is given in sect. II.

SI may be looked at from (at least) two radically different angles; the first concerns the conditions of possibility of SI, or, more plainly, questions like "What conditions must be fulfilled in order for SI to be at all possible ?". The second, equally important, angle focusses on applied and possible strategies in SI, e.g. techniques employed when interpreting from verb final languages into verb second or verb initial languages.

Of course, it is not inconceivable that the problems studied under each heading are somehow related, perhaps even closely so. But that is another empirical issue still to be settled.

\section{SOME CRITICAL REMARKS}

This section briefly discusses one proposed basis for the study of SI which in some respects I find doubtful.

* I am indebted to my colleagues Dr. John Murphy and Prof. Jens Rasmusen for valuable comments and criticisms. 
1. D. Seleskovitch : Separating Language and Thought, Expression and Content.

Consider this passage,

Die Gedanken sind unabhängig von der Sprache, die Formulierung dagegen ist an der Sprache gebunden. Um die eigenen, oft nicht originellen, stets jedoch persönlichen Gedanken verständlich auszudrücken, muss man sich an die Sprachgewohnheiten (Aussprache, Wortwahl, Satzbau) des benutzten Codes halten. Wie man das Gemeinte ausdrückt, hängt also von diesem Code $a b$, nicht aber von der Ausdriicksweise, die ein anderer Code vorschreibt. Soweit wird mir niemand widersprechen [...] (Seleskovitch $1984: 45$. )

Seleskovitch's main tenet is that "der Umkodierungsgedanke", i.e. the idea that SI is performed directly from SL into TL with no intermediate stage, cannot be maintained. Or should not be maintained would be a more accurate way of restating her view, since we are here in a well-known field of debate, where evidence is lacking to setthe the issue ${ }^{1}$. Therefore, arguments of a somewhat more speculative nature are all we can resort to. If cannot be proved that Seleskovitch is wrong, just as she cannot prove that she is right. What we can do is discuss what seems to be the most reasonable epistemological basis for a theory of SI and why.

In the article quoted (which, despite its age, is very representative of her later writings also) Seleskovitch introduces an intermediate stage in the SI process. This stage is represented in the quotation by the phrases "die Gedanken" and "das Gemeinte", and her point is that, in order to get to understand the SI process properly, some such language neutral level must be posited.

\subsection{Language vs Thought}

The first objection to Seleskovitch's supposition of this language neutral and, by implication, language independent level of description is that concepts like 'thought', 'idea', 'what is intended/meant', and similar expressions become devoid of interest from a theoretical point of view the moment they are severed from language. If thoughts, as maintained by Seleskovitch, are language independent, nothing prevents us from claiming that any creature from the amoba to the cleverest ape may thing truly great thoughts, and it is a sheer chance that these thoughts are never made explicit. For any theory of SI it must be a matter of prime importance that its basic concepts apply only within the sphere where SI is possible ; and it is not outside "the human sphere".

\subsection{The Linguistic Sign}

Set up point by point Seleskovitch's model looks like this

1. Undress SL

2. Naked thought

3. Dress naked thought in TL

A second implication of this view is that language must have a mode of existence independently of what it expresses : Language is distilled out, and we are left with "das Gemeinte" ; but then what remains of language? One might consider the possibility that language is an "empty shell" which must then be fitted to something which is not language (such as the stuff ideas are made of) as the need arises. Adopting this view leads to other questions, e.g. "If language is 'pure form' in this sense, how is one supposed to know which linguistic elements to choose in order to express one's ideas and intentions?" or "What is the mechanism like which ensures that the proper expressions go with the proper intentions ?" It seems to me that some vicious form of circularity is involved here, since the "mechanism" supposed to link language (conceived of as an empty shell) with its "content" must itself be a sort of language in which expression and 
content are not severed in this way! Thus nothing seems to be gained from considering language an empty shell, or "pure form" (and I sincerely doubt that Seleskovitch holds this view, but it is an unavoidable consequence of her denunciation of the "Umkodierungsgedanke").

\subsection{Linguistic vs Intended Meaning}

A third corollary of Seleskovitch's assumption of the intermediate stage is that it is in principle possible to distinguish what is meant from what is said, since the two are not necessarily related according to her view.

Consider the well-studied case of a full-blown explicit promise which is broken by the one promising. Are such cases not unambiguous evidence that Seleskovitch is right in assuming that it is not only possible but in fact necessary to distinguish what is said from what is intended? No ! The question is wrongly put : If in a given situation someone says "I promise to buy you a bottle of beer when we meet tomorrow at 3 p.m.", he has willy-nilly made a promise (cf. Andersen \& al. 1976:64) unless other formal or conventional conditions are violated. The speaker's intentions at the moment of speech can never suspend or disqualify the meaning potential of the language (and the obligations thereby assumed by the language user) of the speech community. If this were the case, SI would be, if not impossible, then, at best, a haphazard business, which would go for language use in general as well, since it would be impossible to act rationally in accordance with any form of linguistic behaviour. In other words, a theory of SI should not take as its point of departure that understanding a language is a game of guessing other people's intentions or that speaking is trying to suit an empty language shell to something intended. If speaker intention i.e. "die Gedanken", "das Gemeinte") is arbitrarily separated from the expression of this intention, what can the interpreter do with the linguistic material he gets from the speaker/hearers he is working for? What is to the interpreter "das Gemeinte?" How will he ever know, if it is not inextricably bound up with the linguistic expression on which (more often than not) he has to rely? What I suggest, therefore, is that a theory of SI must necessarily stick to an ancient dogma, viz. that what is intersubjectively recognizable and collectively understandable are the linguistic conventions of a speech community.

To sum up. The arguments that can be adduced against Seleskovitch's proposed separation of thought and language are fairly strong. Especially in view of the fact that this separation is intended to be the basis of a theory of SI. SI theory seems to me to be the field to avoid separating language and intended meaning.

\subsection{Language as Convention}

Seleskovitch emphasizes that the expression chosen in a TL rendering is not determined by the choice of linguistic expression in SL. From one point of view, this seems to be an entirely plausible statement, i.e. if one concentrates on the lexical side of languages. There is no doubt that languages vary in numberless unpredictable ways as regards lexical structures, and it would be downright foolish to deny the fact.

What might relevantly be added, however, is that languages are more than lexical structures realized in speech. And, turning again to the formal side of language(s) it might be reasonable to emphasize that not all aspects of SL and TL are quite as unpredictable and dissimilar, as the picture painted on the basis of lexical considerations might lead us to believe. What I should like to propose as an integral part of future SI research is the study of formal syntax.

The theory of the form of human language in its Chomskyan version is a universalist theory of language which will, it is hoped, lead to a deeper understanding of the common core of human languages. For the SI researcher universalist theories neces- 
sarily form a field of primary interest, since presumably, the very existence of linguistic universals whichever they may eventually turn out to be, constitutes the condition of possibility for SI and interpreting in general.

In other words, the only way to explain the fact that interpreting (and translating, for that matter) from one human language into another is at all possible, is by assuming the existence of linguistic universals. Or the argument may be turned upside down : the reason why interpreting cannot be carried out from Black Bird (SL) into a natural language (TL) is that the elements constituting the former "language" do not belong to the same set of universals as the elements of human languages. Of course, if has often been observed that a black bird when threatened by a cat or an owl, utters its characteristic shrill sounds, and as observers we may "interpret" (different sense now) these signals as some sort of symbolic behaviour, a conditioned reflex. But it is never possible for us to say whether the black bird "meant" "Danger !", "Fat owl on the move!", "Let's get out of here !" or something entirely different. A situation like that never occurs when SI-ing. A linguistic expression typically means something, presupposes something, and implies something. A black bird's cry does nothing of the sort.

Vis-à-vis this universalist approach to the study of human language stands the one proposed by Seleskovitch, which entails that languages can most profitably be regarded as unrelated sets of conventions, and that this is what the practising interpreter should take as his point of departure when actually interpreting. I am sure that very good arguments can be advanced in favour of this interpreting strategy. If, however, it is a goal of SI theory to try to account for the actual functioning of the interpreter's brain in the process of interpreting, it is less than obvious that the SI researcher should stress linguistic differences rather than similarities among human languages. Thus I would propose that from a syntactic point of view the basic hypothesis should be not that the interpreter has "a free choice" as to the form of his interpretation, but rather that the linguistic form of the TL version is influenced by a finite set of relations of a formal nature between SL and TL which are predictable in principle. To the extent that this view can be corroborated, the conception of a "free choice" on the part of the interpreter increasingly becomes a beautiful dream.

By recent developments in formal syntactic theory we seem to have come closer to an understanding of the way human languages are related formally. The main tenet now is that relations among human languages can be explained in terms of a number of intricate parametric variations. In practice this implies that bilingualism, whether natural or acquired, should be understood as mastery of the parameters that characterize the languages involved. Hence we must assume that a speaker does not double the number of parameters in his brain when moving from monolingual to bilingual. The "natural procedure", as it were, is to assume that any possible intersection of parameters defined by Universal Grammar, will be what is represented in the brain. It is hardly likely that speakers have "copies" of parameters.

If this, rather robust, interpretation of the basic assumptions of formal syntactic theory is accepted, it follows that, to an extent which is specifiable in principle, there must be some sort of determining relation from any SL to any TL. Or to adapt Seleskovitch's mode of expression : How the interpreter expresses "das Gemeinte" may well turn out to be determined by the linguistic form of another code, i.e. that of the SL.

\section{ERROR TYPOLOGIES AND THE CONCEPT OF 'SAMENESS'}

A favourite topic in SI research is the so-called error typologies, whose rationale has been formulated by Henderson, among others, "(...) a typology of errors ought at least in theory to point us in the direction of some of the underlying characteristics of the mental processes involved (...)" (Henderson $1982: 22$ ). I agree with him that it is 
reasonable to nourish that sort of hope, only, there are certain clear preconditions that must be fulfilled in order for this optimism to be justified, since it is by no means selfevident that there is anything but a spurious relationship between a given error typology and mental processes involved in SI. This section treats some of those preconditions.

To construct a typology is to categorize. To categorize is to ascribe members to a set; this can be expressed as a "maxim" for typologizing :

Maxim I : A typology is useful proportionately to the extent its concept of 'sameness' is useful.

By way of illustration let us consider two typological bases whose concepts of 'sameness' differ radically : first a version of what might be labelled traditional functional grammar, and second a more recent theory of grammar.

\section{Traditional Grammar and the Concept of 'Sameness'}

Consider the following sample of English and Danish sentences.

(1) A Your interest in Bill surprised me

B *Who(m) did your interest in surprise me?

Da. ${ }^{*}$ Hem overraskede din interesse i mig?

(2) A The boy that met Bill disappeared

B *Who did the boy that met disappear?

Da. ${ }^{*}$ Hem forsvandt drengen der mdte?

(3) A The job was easier than the manager had promised the boy that it would be

B *Which boy was the job easier than the manager had promised that it would be?

Da. ${ }^{*}$ Hvilken dreng var opgaven nemmere end formanden havde lovet den ville vare?

(4) A The one of all his daughters that I hate wants to marry me

B *The one of all his daughters wants to marry me that I hate

Da. ${ }^{*}$ Den af hans døtre vil gerne gifte sig med mig som jeg afskyr.

(The Danish sentences are translations of the English B- sentences and show the same pattern of acceptability.)

Let us assume that (1) - (4) are to be accounted for by an error typology based on a traditional grammatical analysis of sentence and construction types.

This typology would emphasize the fact that in the English sentences in (1), (2) and (3) the same "process" is involved, i.e. Question Formation. Further, in each case the declarative construction matching the question differs from the others : in (1) we have a simple declarative sentence, in (2) a relative clause in involved, and in (3) a comparative construction. Accordingly, this error typology will ascribe the errors in the Bsentences to lack of proficiency in Question Formation. This is the common characteristic of the three examples, which makes them ascribable to the same type. There is not likely to be a more systematic explanation of the fact that the errors appeared in such different construction types as was the case. Therefore, if it is further assumed that the 
same individual who made the mistakes in (1) - (3) makes the error illustrated in (4 B), this error cannot be included under the type 'Question Formation', since no question is involved at all : it must, according to this analysis, belong to a different type, say, "Errors made in sentences involving Extraposition from a Noun Phrase".

\section{Formal Syntax and the Concept of 'Sameness'}

What is interesting from our point of view is that it is in fact possible to offer a unified explanation of the errors made in the above sentences, thereby making the claim of a close correlation between error typologies and mental processes more probable - at least in theory.

Assume the rough analyses of the B-sentences listed below

(1 $\left.\mathrm{B}^{\prime}\right)$ who(m) $[\mathrm{S}[$ (NP) your interest in $\times \quad \beta \gamma$

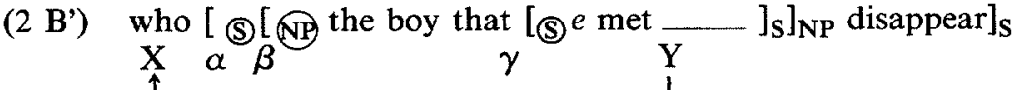

which boy [@ the job was easier than $[\subseteq$ the manager $\mathrm{x} \quad \gamma$

had promised - Y

(4 B') the one of his daughters

that I hate

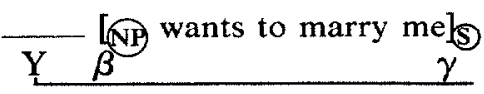<smiles>CC[Al]1CCCCC1</smiles>

(X, Y and the Greek letters have been inserted to facilitate application of the Subjacency Principle given below : $e$ in ( $\left.2 \mathrm{~B}^{\prime}\right)$ indicates that the subject position in the relative clause is empty.)

If the sentence are analysed in this way, it becomes apparent that the common characteristic of the four structures is that two clause positions are "related" across at least two constituent boundaries of the type Noun Phrase or Sentence. In this specific sense the same error has been made in all four structures, and, accordingly, in this typology they will be listed under the same heading as violations of a principle which is usually given the following form (cf. e.g. Chomsky $1975: 85$ for a readily comprehensible explanation of the principle).

\section{Subjacency Principle}

No rule can relate positions $\mathrm{X}$ and $\mathrm{Y}$ (in any single rule application) in a structure like $\left[\begin{array}{lll}\alpha & \ldots \\ X\end{array}\right.$

By principles like this whose validity is very general and whose explanatory value far exceeds that of any rule of traditional grammar we may eventually develop error typologies for certain modules of SI, typologies which do not merely list errors, but by their definition of 'Sameness', are able to relate errors in a principled way. Only thus can we hope to substantiate the claim that error typologies throw light on mental processes ${ }^{2}$. 


\section{PARAMETERS OF LINGUISTIC VARIATION - MAXIM II}

In (1) - (4) I gave Danish translations of the asterisked English structures, and it turns out that the Danish sentences were as bad as the English ones.

For illustrative purposes let us assume that the Subjacency Principle is an example of a parameter for natural languages, i.e. a variable which may under specifiable circumstances take on different values, say + or -. In Universal Grammar this amounts to a hypothesis that the Subjacency Principle forms part of our innate linguistic equipment, and any natural language will be related to this principle either by obeying it or by not obeying it ${ }^{3}$. Judging by the examples given above, Danish as well as English seem to obey the principle, that is, both languages are hypothesized to be subject to its implied restrictions on possible structures.

Maxim II : An error typology is useful only insofar as its basic principles shed light on relations between linguistic structures in two or more languages in which no errors occur.

\section{Greenberg's Quantitative Universals}

It is now possible to expand this somewhat programmatic picture of what a theory of the Formal Module of the SI process might lead to in some distant future.

In his seminal article "Some Universals of Grammar with Particular Reference to the Order of Meaningful Elements", Greenberg notes that there seems to be a statistically significant relation between the prevalence in a given language of a certain word order in declarative main clauses and the occurrence of certain other construction types. If, for example, a language shows the predominant pattern of Verb-Object (VO) order in declarative main clauses, this language also, in the unmarked case, shows relative clauses following their antecedents, modifying adjectives following their head nouns, possessive expressions following their heads, etc. On the other hand, in OV languages relative clauses (once again we consider only the unmarked case) will typically precede their antecedents, which same position is taken by modifying adjectives, possessives, and so on ${ }^{4}$.

We have only a very poor understanding of what it is that relates these linguistic structures so intimately. Nonetheless, it does not seem unreasonable that somehow it will be possible to uncover structural principles like the Subjacency Principle which may explain such structural dependencies as are at present but lists.

If this is in fact possible, it follows that meaningful content can be accorded to a "generalized parameter" like

$$
+\mathrm{VO}
$$

Depending on the value of the parameter chosen by a particular language, the unmarked structures of this language would now follow like theorems from an axiom, and this axiom is our formalized picture of possible mental processes (in the Formal Module) when interpreting.

We might carry the thought experiment even further in more concrete terms : for SI theory and our error typology a structural understanding of the above statistical relations would reveal precisely which other error types are also to be expected once one type has been recorded in a certain interpreter. And last but certainly not least, it might be envisaged that a structural understanding of the sort here mentioned would bring about new insights in the much-studied but poorly understood phenomenon of anticipation in verb final languages, i.e. there could be structural reasons why in practice anticipation seems to be no problem at all. 


\section{Notes}

1. For a recent article on some of the problems involved, see J.C. Bishop (1983) and the references cited therc.

2. Recent research has shown that the Subjacency Principle may not after all be so good a candidate for Universal Grammar as was previously supposed; Scandinavian languages, for instance, have clever means to curcumvent the principle in Topicalization and Reflexivization cases to mention but two.

3. Of course languages tend to be more complicated than this : here I am taking the easiest way out in order to underscore my general point that SI research will have to incorporate somehow considerations much like those of formal grammar. Otherwise its claim about the explanatory adequacy of SI error typologies for mental processes is hardly credible.

4. I cannot go into detail with these points; the interested reader is referred to Greenberg's article and to Lehman (1972:55 ff) for instructive examples from Japanese and Portuguese as representatives of $\mathrm{OV}$ and VO languages, respectively.

\section{REFERENCES}

ANDERSEN, J., B. CONRAD, T. HARP $\emptyset$ TH, P.A. JENSEN, S. SVAGIN \& J. SVENDSEN (1976) : "Om Searles talehandlingsbegreb og dets anvendelighed", in PAPIR II, 5 .

BISHOP, J.C. (1983) : "Can there be Thought without Language?", in W. Maxwell (ed.).

CHOMSKY, N. (1975) : Reflections on Language, N.Y., Pantheon.

GREENBERG, J. (1963a) : "Some Universals of Grammar with Particular Reference to the Order of Meaningful Elements", in Greenberg (1963b).

GREENBERG, J. (ed.) (1963b) : Universals of Language, Cambridge, Mass., MIT Press.

HENDERSON, J. (1982) : "Some Psychological Aspects of Simultaneous Interpreting", in Fremdsprachen, I.

KAPP, V. (Hrsg.) (1974) : Übersetzer und Dolmetscher, Heidelberg, UTB, Quelle \& Meyer.

LEHMAN, W.P. (1972) : Historical Linguistics : an Introduction, N.Y., Holt, Rinehart \& Winston.

MAXWELL, W. (1983) : Thinking. The Expanding Frontier, Philadelphia, Pennsylvania, The Franklin Institute Press.

SELESKOVITCH, D. (1974) : "Zur Theorie des Dolmetschens", in V. Kapp. 